\title{
Cardiac resynchronization therapy is certainly cardiac therapy, but how much resynchronization and how much atrioventricular delay optimization?
}

\author{
Andreas Kyriacou • Punam A. Pabari • \\ Darrel P. Francis
}

Published online: 28 July 2011

(c) The Author(s) 2011. This article is published with open access at Springerlink.com

\begin{abstract}
Cardiac resynchronization therapy has become a standard therapy for patients who are refractory to optimal medical therapy and fulfill the criteria of QRS $>120 \mathrm{~ms}$, ejection fraction $<35 \%$ and NYHA class II, III or IV. Unless there is some other heretofore unrecognized effect of pacing, the benefits of atrio-biventricular pacing on hard outcomes observed in randomized trials can only be attributed to the physiological changes it induces such as increases in cardiac output and/or reduction in myocardial oxygen consumption leading to an improvement in cardiac function efficiency. The term "Cardiac Resynchronization Therapy" for biventricular pacing presupposes that restoration of synchrony (simultaneity of timing) between left and right ventricles and/or between walls of the left ventricle is the mechanism of benefit. But could a substantial proportion of these benefits arise not from ventricular resynchronization but from favorable shortening of AV delay ("AV optimization") which cannot be termed "resynchronization" unless the meaning of the word is stretched to cover any change in timing, thus, rendering the word almost meaningless. Here, we examine the evidence on the relative balance of resynchronization and AV delay shortening as contributors to the undoubted clinical efficacy of CRT.
\end{abstract}

Keywords Atrio-ventricular optimization - CRT $\cdot$ Heart failure

\footnotetext{
A. Kyriacou ( $₫)$ - P. A. Pabari · D. P. Francis International Centre for Circulatory Health, National Heart and Lung Institute, Imperial College London, 59-61 North Wharf Road, Paddington, London W2 1LA, UK e-mail: andreas.kyriacou@imperial.ac.uk
}

A. Kyriacou - P. A. Pabari - D. P. Francis

St. Mary's Hospital, Paddington, London, UK

\section{Introduction}

The short-term hemodynamic effects of cardiac resynchronization have been demonstrated in a number of small studies over the last 15 years.

Cardiac resynchronization therapy has improved outcomes of patients who have persistent substantial LV dysfunction and/or symptoms on optimal medical therapy and have $\mathrm{EF}<35 \%$, QRS $>120 \mathrm{~ms}$ and are in sinus rhythm [1-6].

However, it is far from clear whether the beneficial effects of CRT are a result of the inter/intra ventricular resynchronization or a result of the shortening of the long intrinsic AV interval, very commonly present in these patients, or indeed a varying combination of the two.

\section{Pathophysiology of the failing heart}

Unlike a healthy heart with isolated conduction disturbances, in which suboptimal efficiency may impair its function but not lead to impairment of physical capacity or survival, the dilated failing heart may be operating on a knife-edge in which even apparently minor inefficiency is compounded by adverse feedback processes in a way that impairs capacity and worsens survival. Suboptimal AV and VV conduction are examples of such additional inefficiencies [7].

The numerous compensatory mechanisms, neurohormonal and mechanical, are chronically activated in heart failure. Sympathetic tone is high and contributes the remodeling of the myocardium which results in geometrical modifications and increased wall stress.

With time, hypertrophy and/or apoptosis occur in response to this increased stress and myocardium is 
replaced by fibrotic tissue [8]. As the function decreases further, filling pressures rise resulting in congestion. Mitral filling adopts a restrictive pattern [9].

Development of conduction abnormalities contributes to this vicious cycle by regional desynchronization. The effect of inter-atrial and inter-ventricular conduction delays is to generate ineffective left- and right heart atrioventricular delays. This decreases efficiency of transport of blood from atrium to ventricle, and precipitates mitral and tricuspid regurgitation. Interventricular conduction abnormalities also cause paradoxical septal motion; meanwhile, extensive intraventricular delays, such as LBBB, result in reduced global ventricular function and impair both systolic and diastolic behavior.

Clearly, to maximize efficiency of function, the fourchamber heart requires not only synchrony within and between ventricles, but also optimal atrioventricular delay. The latter cannot rationally be termed synchrony (simultaneous timing) because the intention is definitely not to have simultaneous atrial and ventricular contraction. Although it might be argued that the "synchrony" should be stretched to accommodate any change in time (not specifically making timing simultaneous), there are two reasons not to do so. First, such a habit, of using words to mean their own opposite, is linguistically described as irony and, while commonplace in politics, is an unconventional approach in science and is particularly unusual in naming a therapy in medicine. Second, patients benefit when clinicians understand words and concepts when they read or hear them. When the procedure of biventricular pacing is superseded by the (longer) name cardiac resynchronization therapy, a clinician might reasonably suppose that the newer name must have been adopted because it is more precise, and so conclude that the purpose of the procedure is to bring the ventricular walls into a closer timing relationship with each other. If this turns out not to be the dominant benefit of biventricular pacing, the choice to impose the name "resynchronization" is doing patients a disservice.

\section{Consequence of a long AV interval and ventricular dyssynchrony on mitral flow and effective LV filling time}

In prolonged $\mathrm{AV}$ conduction, mitral regurgitation can occur in late diastole [10]. This "presystolic mitral regurgitation" was initially observed in patients with complete heart block and normal ventricles. It occurs because atrial systole finishes but ventricular systole does not start immediately: this occurs whenever the AV interval is long.

Doppler echocardiography detects this atrioventricular valve regurgitation in the last diastolic or presystolic period, in patients with complete or first-degree heart block [11]. Tricuspid and mitral regurgitation are equally common $[12,13]$.

Patients with wide QRS can also have presystolic mitral regurgitation as a consequence of prolonged isovolumic contraction and relaxation times. Wide QRS due to LBBB prolongs mitral regurgitation (by sometimes over $100 \mathrm{~ms}$ in patients with $\mathrm{EF}<35 \%$ ) beyond that caused by a long AV interval alone [14-17].

Impact of prolonged $\mathrm{AV}$ and wide $\mathrm{QRS}$ on ventricular filling time

Xiao et al. cast a spotlight on left ventricular filling time in heart failure. Prolonged AV and wide QRS each decrease LVFT and thereby reduce stroke volume [14-17].

A prolonged AV interval reduces net volume of blood pumped by the ventricle by 2 mechanisms. First, it allows presystolic mitral and tricuspid regurgitation to take place, which means that net forward flow across those valves is smaller than it might otherwise be. Second, long AV time causes fusion of the E and A waves reducing LVFT and thus, cardiac output (Fig. 1).

Wide QRS (causing or worsening mechanical dyssynchrony) also impairs LVFT additional to the effect of long AV delay. Wide QRS prolongs isovolumic contraction time (IVCT) and isovolumic relaxation time (IVRT) by impairing the rate of rise and fall of pressure in the ventricle. Since LVFT is the remnant of the RR interval after the "bites" taken by ejection time (ET), IVCT and IVRT, all three of which may be prolonged, LVFT has three reasons to be compressed in patients with poor cardiac timings.

Finally, long IVCT and IVRT also prolong the potential for mitral regurgitation to occur while blood is not being ejected forward, thus worsening the balance of blood ejected forward versus backwards from the ventricle.

Physiological impact of shortening AV delay

by atrio-biventricular pacing

CRT can both shorten AV delay and reduce any ventricular dyssynchrony. Pacing by programming the AV delay to a shorter interval alters timing of ventricular contraction with respect to the onset of atrial contraction and ejection. This timing, and its effects on LVFT, has been shown to be important [18] and it is unlikely to be less important in patients with failing hearts. Shortening a prolonged intrinsic AV interval by pacing, increases ventricular preload at the onset of systole and reduces regurgitation. This manifests as increased stroke volume and cardiac output. 


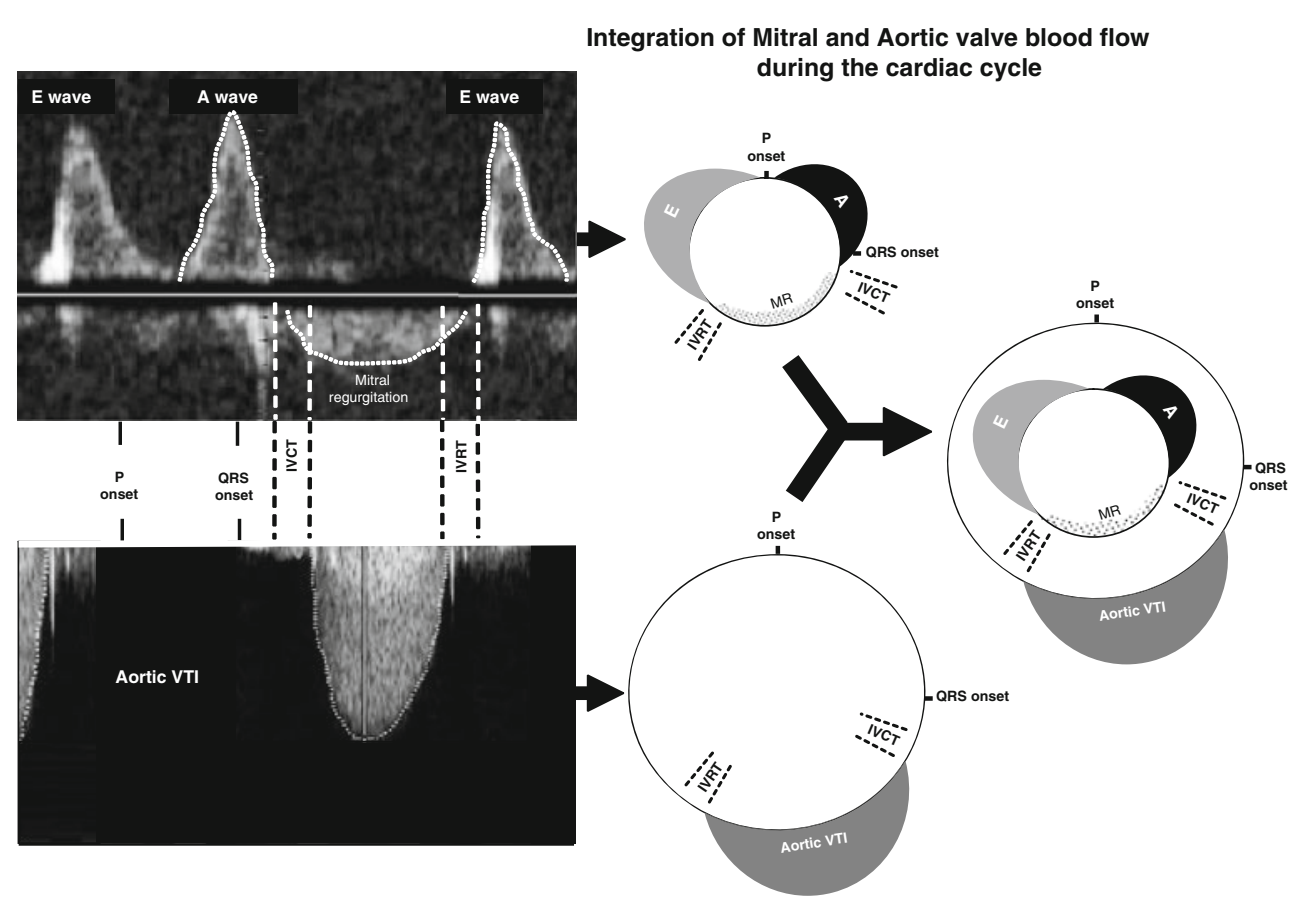

Fig. 1 A schematic illustration combining the transmitral and aortic flow during the cardiac cycle. To simplify understanding of Doppler flows (left), they can be sketched wrapped into a circle, representing the cardiac cycle, starting with atrial activation (" $P$ onset"). The mitral (top) and aortic (bottom) flow traces are inscribed upon inner and outer circles, which can be combined into a single diagram (right). This allows clear demonstration of the interaction between timings of activation, forward flow, mitral regurgitation and isovolumic contraction and relaxation times (IVCT and IVRT)

with a narrow QRS have a better LVFT for the same heart rate. However, in these patients, with increasing heart rate LVFT falls more dramatically and stroke volume drops significantly [19].

So, once ventricular resynchronization has occurred, the LVFT improves but when patients are, for example, exercising and heart rate increases, the LVFT may start to fall [19] dramatically. This rate of fall in LVFT with increasing heart rate can be slowed down by adjusting the AV delay (rate adaptive pacing). Although the most obvious approach is to shorten the AV delay, interestingly, a review [20] of the very few studies available, has suggested that this is not universally true; in some patients, the AV delay may need to be prolonged or left unchanged for best cardiac output.

Nevertheless, if $\mathrm{AV}$ is not adjusted as the heart rate increases, the fall of stroke volume and consequently blood pressure becomes progressively larger [21-24].

To cast light on which of the two components of biventricular pacing (AV optimization or ventricular resynchronization) is more dominant in improving hemodynamics and clinical endpoints, one has to look carefully at the existing evidence from (a) small invasive studies that assessed the acute hemodynamic benefits of CRT and (b) large randomized clinical trials. 


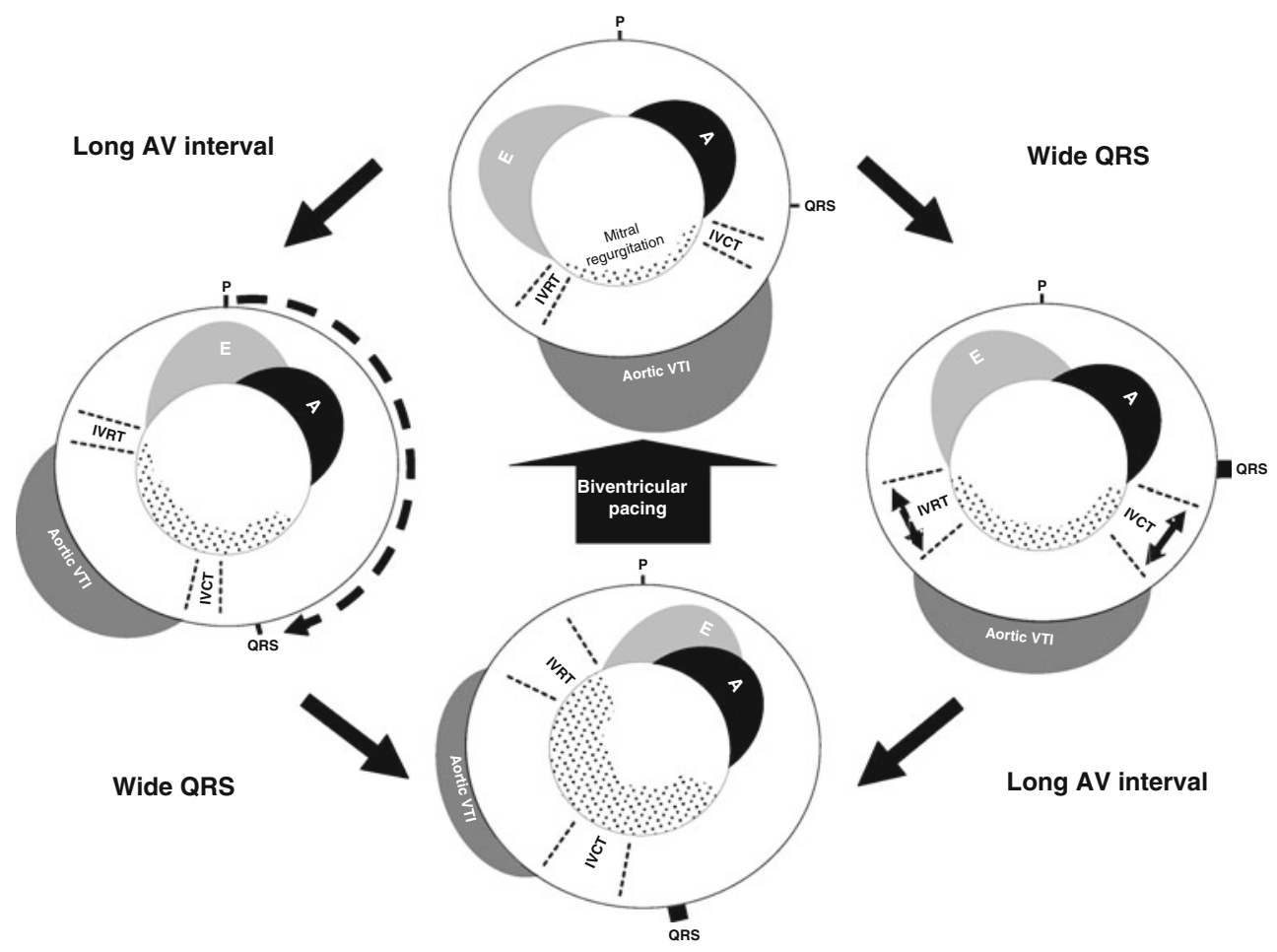

Fig. 2 A schematic illustration of the effects of long AV interval, wide QRS width and biventricular pacing on stroke volume. Each sketch shows transmitral (inner circle) and transortic (outer circle) blood flow, with in each case atrial activation fixed in time at the top (" $P$ "). The top sketch illustrates blood flow in a subject with normal AV delay and narrow QRS. A prolonged AV interval (left sketch) delays aortic ejection thereby permitting presystolic mitral

\section{Results from acute studies}

Shortening a prolonged AV interval in dilated cardiomyopathy by atrially sensed RV pacing was demonstrated to be beneficial [25], long before biventricular pacing was introduced as a mode of treatment. In patients with heart failure and sinus tachycardia with fused $\mathrm{E}$ and $\mathrm{A}$ waves, shortening of the AV delay during atrial-sensed RV pacing reduced the duration of mitral and tricuspid regurgitation and lengthened the LV filling time [26]. Shortening the AV interval also raised exercise duration and maximum oxygen consumption and reduced the sensation of breathlessness at peak exercise. Another group of investigators performed atrially sensed RV pacing in patients with severe LV dysfunction and long intrinsic AV delays. The benefit of AV shortening was only evident in those patients with very prolonged intrinsic AV intervals [27].

A study that looked at the response of patients paced in AAI and with an intrinsic wide QRS and very long AV delays showed that atrially sensed RV pacing increased the cardiac index by $18 \%$, which was half as much as the increase $(35 \%)$ that atrially sensed biventricular pacing produced at the optimal AV delay. With RV pacing, left regurgitation and delaying $\mathrm{E}$ wave onset resulting in fusion with the following A wave. A wide QRS (right sketch) causes prolonged IVCT and IVRT, reducing left ventricular filling time and worsening MR. When prolonged AV interval and wide QRS co-exist (bottom sketch), their effects on MR are additive and devastating. Atrio-biventricular pacing corrects both electrical abnormalities and thereby improves stroke volume

ventricular dyssynchrony is clearly not being corrected (and may actually be aggravated) yet there was a significant hemodynamic improvement suggesting that AV shortening, in that group of patients, was responsible for approximately $50 \%$ of the improvement [28].

The PATH-CHF [29] investigators found that shortening AV delay of patients by with RV pacing achieved improvements in LV dP/dtmax, Aortic SBP and pulse pressure that were $\sim 25-50 \%$ of the improvements achieved with full biventricular pacing. Although the improvement in hemodynamics by RV pacing was less than by biventricular pacing, it was far from 0 , suggesting that shortening AV delay (which is always part of biventricular pacing) could contribute importantly in the hemodynamic improvements seen during biventricular pacing.

Others found less convincing evidence that atrially sensed RV pacing offers any acute benefits at all when compared with baseline. In a study [30] of 12 patients with narrower QRS, there was no benefit from atrially to sensed RV pacing. However, in such patients with narrow QRS, $\mathrm{RV}$ pacing induces LV dyssynchrony and therefore impairs $\mathrm{LV}$ function, as demonstrated in that study. When the AV delay was shortened, there were progressive improvements 
in hemodynamics, with the optimal AV delay reaching the values of the intrinsic hemodynamics: just managing to compensate for the ventricular dyssynchrony caused by the $\mathrm{RV}$ pacing.

Another group of investigators [31] reported that in patients with wide QRS and prolonged AV delay, atrially sensed biventricular or LV pacing showed significant improvements in LV dP/dt max. Atrially sensed RV pacing, though, it showed a trend to improved hemodynamics (at the optimal AV delay) of approximately 30-50\% of that of biventricular pacing, this was not statistically significant. We cannot tell from that study alone whether atrially sensed RV pacing makes a substantial contribution, due to a limited statistical power.

So far we have discussed the impact of atrially sensed $\mathrm{RV}$ pacing versus atrially sensed biventricular/LV pacing on acute haemodynamics in patients with $\mathrm{EF}<35 \%$, long intrinsic AV intervals and evidence of dyssynchrony (wide QRS, commonly LBBB).

Looking at the effects of atrially sensed RV pacing, which is not favorable (in fact, potentially aggravating) for correcting ventricular dyssynchrony, can give insights of the contribution of optimization AV delay. In the studies above, it seems that the acute improvement by atrially sensed RV pacing pacing at the optimal AV delay, for example in LV dP/dtmax, can be $30-50 \%$ of that achieved by complete biventricular pacing: AV optimization may not be the dominant component, but neither is it trivial.

Even though in most of the invasive studies mentioned above the optimal AV delay tended to be between 100 and $120 \mathrm{~ms}$ shorter than the intrinsic AV interval, assessing the pure effect of shortening AV delay during biventricular/LV pacing is difficult. This is because during the process of AV shortening there are, initially, changes in the LV pre-excitation pattern and therefore ventricular resynchronization.

The two are so closely linked that it is very difficult to decide at which point the "ventricular resynchronization" is maximal and subsequent effects are purely due to AV shortening.

In reality, both $\mathrm{AV}$ optimization and $\mathrm{VV}$ synchrony contribute simultaneously; the relative balance is likely to be different between patients, due to different intrinsic AV intervals, severity of ventricular dyssynchrony, and pacing site (RV apex/septum, LV anterior/lateral [32] etc.).

Hemodynamic curves shown in many of the studies described above support this impression.

Whether LV and biventricular pacing are different is less certain. In theory, appropriately timed LV pacing can create fusion with intrinsic conduction, giving a similar effect as biventricular pacing. If intrinsic AV delay is long, this ideal timing of LV pacing may also be long, and so shorter delays such as $80-100 \mathrm{~ms}$ might be too short, causing the QRS to widen again, the ventricles to become more dyssynchronous and hemodynamics to worsen [33]. As a result any benefits from AV optimization, by shortening the AV delay may be offset by ventricular desynchronization.

In atrially sensed biventricular pacing, however, ventricular resynchronization is not dependent on intrinsic conduction because the two pacing leads in RV and LV mean there is less reliance on an intrinsic contribution to activation. With biventricular pacing, greater shortening of the AV delay can be achieved without there being an obligatory cost of inducing ventricular dyssynchrony [34].

\section{Do the results from the clinical trials support $\mathrm{AV}$ optimization to be an important determinator of CRT benefits?}

There are no clinical trials to date allowing us to assess the efficacy of RV DDD versus BIV DDD, in patients fulfilling current criteria for CRT.

PACE [35], a small randomized study, of patients with normal EF (no dyssynchrony) and with indications for conventional dual chamber pacing, compared the effects of atrially sensed RV versus biventricular pacing. It reported that $50 \%$ of RV-paced patients developed dyssynchrony, and at 6 months, RV-paced patients had an absolute reduction in ejection fraction by $7.1 \%$, but no observed differences in functional tests, such as 6MWT and QoL (SF-36) questionnaire, were found between RV and biventricular pacing. However, this study was small and short, therefore underpowered to find any true differences between arms. More importantly, it did not address the clinical effect of AV optimization by atrially sensed RV pacing in an already dyssynchronous ventricle versus biventricular pacing.

In addition, larger trials such as BIOPACE and BLOCK$\mathrm{HF}$, which will release results in the next 2-3 years, have been recruiting similar patients to PACE, and therefore have the same limitation.

As a result, it is not yet possible to use this approach, as we have done with the smaller acute studies above, in order to quantify the difference in benefits of AV optimization in an already dyssynchronous ventricle (during atrially sensed $\mathrm{RV}$ pacing) from the benefits of both AV optimization and VV synchronization (during atrially sensed biventricular pacing).

One other approach of assessing how important AV optimization is versus VV synchrony is to compare the effect of CRT in patients in AF (no AV delay to be impaired, so pure VV resynchronization) versus patients in SR (AV optimization with VV resynchronization). Bigger effects of CRT in SR than in AF would suggest that in SR, a substantial element of AV optimization is involved. 
Although there are multiple randomized controlled trials evaluating of CRT in SR, these are lacking for AF. It is therefore a challenge to try and establish the true benefits of CRT in the AF population. A meta-analysis [36] of the few prospective cohort studies looking at the effects of CRT between AF and SR patients suggest that there is clinical improvement in both AF and, as expected, in SR patients when compared to baseline. However, the AF CRT group of patients showed a relative improvement in the $6 \mathrm{~min}$ walk test $50 \%$ of that of SR CRT, Minnesota quality of life $73 \%$ and NYHA class $90 \%$ of that of SR CRT.

Ejection fraction was relatively slightly higher in AF by $5 \%$. However, the authors noted that there was a significant degree of heterogeneity for this outcome.

One other meta-analysis [37] has also shown that the benefit from CRT obtained by patients with SR was greater than that obtained by patients with AF with respect to 6-MWT and quality of life. No difference in benefit was detected between the SR and the AF patients for NYHA class improvement or for ejection fraction.

There are, however, a number of limitations from these meta-analyses. Selection criteria and baseline characteristics of patients in different groups varied between the studies. As much as $20 \%$ of SR patients developed AF, who in the medically treated SR group, was not reliably identified. Also rate control of AF patients in the CRT group varied from just medical management to AVN ablation.

Perhaps the most convincing evidence that SR CRT may be superior to AF CRT comes from a subanalysis [38] of CARE-HF. It shows the same consistent trend, albeit statistically non-significant. Some patients spontaneously developed AF post-randomization, which was unrelated to which arm they were randomized to. The two post hoc groups, AF and SR, happened to have very similar baseline characteristics, making it possible to informally compare the effect of CRT between the AF and the SR patients. As shown in Table 1, the AF group showed a consistent trend to weaker effects of CRT than in SR patients. For example, the numerical value of mortality or unplanned hospitalization for a cardiovascular event reduction was in AF 64\% of that of SR, emergency hospitalization from cardiovascular causes $47 \%$. Improvement of ejection fraction in $\mathrm{AF}$ was $50 \%$ of that in SR, and elevation in pulse pressure was $40 \%$ of that of SR.

Predictors of response: QRS, echocardiographic dyssynchrony or long PR?

Although, QRS width, "electrical dyssynchrony" is at best a crude proxy for mechanical ventricular dyssynchrony, it has been shown in MADIT CRT [39], REVERSE [40] and PROSPECT [41, 42] trials to be a predictor of response to
CRT. Conversely, in the PROSPECT trial, mechanical dyssynchrony by various echocardiographic markers was not found to be predictor of response.

There are two potential reasons why QRS may be a better predictor than echocardiography. Firstly, QRS width is a simple and highly reproducible measure when carried out automatically, whereas the echocardiographic measures used for dyssynchrony assessment may suffer from poor reproducibility and also from variability in methods between test centres [41, 42].

Second, it could be argued that ventricular resynchronization by pacing is an electrical intervention attempting to reorganize electrical conduction and this occurs immediately after implantation [43]. Prerequisite to success is the presence of adequate viable myocardium and anatomically suitable placement of LV pacing lead. If there is echocardiographic evidence of ventricular dyssynchrony but its origin is not electrical dyssynchrony, then it is possible that pacing might be fundamentally unable to correct the ventricular dyssynchrony.

Most trials that showed endpoint benefits of CRT used only wide QRS as a marker of mechanical dyssynchrony and did not require confirmation by echocardiographic measures.

The RETHINQ trial [44], in contrast, which enrolled patients with narrow QRS ( $<130 \mathrm{~ms})$ but with mechanical dyssynchrony on echocardiography, failed to show any difference between the CRT group and the control arm. Within this trial, patients with QRS width of 120-130 ms had a significant benefit over the control group, compared to the non-significant change in patients with QRS $<120 \mathrm{~ms}$; strengthening the argument of using QRS for better predicting the response of CRT, an electrical intervention.

A sub-analysis of CARE-HF [45] also suggested that a long intrinsic AV interval at baseline is a strong predictor of more unfavorable outcomes and this was still the case after 3 months of CRT. This would suggest that shortening of intrinsic AV interval (i.e., more effective AV optimization) is coupled with more successful CRT.

\section{Chronic studies of VV optimization}

There are three studies that appear to provide data on longterm effects of optimization of VV delay of CRT pacemakers. However, all these studies were conducted in sinus rhythm and therefore we do not know for certain that the changes observed are purely due to changes in VV delay and not from the simultaneous effects on AV delay (on one side of the heart or the other).

First, the Decrease-HF [46] study provided a comparison of a fixed $0 \mathrm{VV}$ delay against a VV delay determined by a formula based on electrical measurements during 
Table 1 Calculation of the proportion of the benefit seen in sinus rhythm $(S R)$ patients that is seen in atrial fibrillation $(A F)$ patients, in the CARE-HF trial

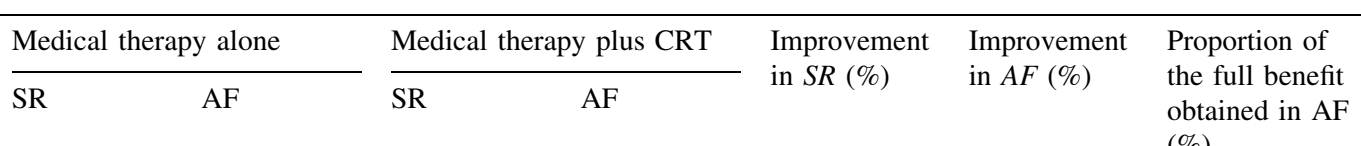

(\%)

\begin{tabular}{|c|c|c|c|c|c|c|c|}
\hline \multicolumn{8}{|l|}{ Outcome } \\
\hline \multicolumn{8}{|c|}{ Primary outcome of main trial, $n(\%)$} \\
\hline $\begin{array}{l}\text { Death or unplanned } \\
\text { hospitalization for a } \\
\text { cardiovascular event }\end{array}$ & 51.2 & 81 & 34.1 & 63.6 & 33.4 & 21.5 & 64.3 \\
\hline $\begin{array}{l}\text { Unplanned } \\
\text { hospitalization for a } \\
\text { cardiovascular event }\end{array}$ & 41 & 72.4 & 25.1 & 59.1 & 36.8 & 18.4 & 47.4 \\
\hline \multicolumn{8}{|c|}{ Secondary outcome of main trial, $n(\%)$} \\
\hline Death from any cause & 28.3 & 37.9 & 19.2 & 24.2 & 32.2 & 36.1 & 112.4 \\
\hline $\begin{array}{l}\text { Death from any cause or } \\
\text { unplanned hospitalization } \\
\text { with worsening heart } \\
\text { failure }\end{array}$ & 44.2 & 65.5 & 26 & 43.9 & 41.2 & 33.0 & 80.1 \\
\hline $\begin{array}{l}\text { Unplanned } \\
\text { hospitalization with } \\
\text { worsening heart failure }\end{array}$ & 30.1 & 50 & 14.9 & 31.8 & 50.5 & 36.4 & 72.1 \\
\hline \multicolumn{8}{|c|}{ Continuous outcome at 18 months, mean } \\
\hline NYHA class & 2.9 & 2.9 & 2.3 & 2.6 & 20.7 & 10.3 & $\mathbf{5 0 . 0}$ \\
\hline $\begin{array}{l}\text { Minnesola living with } \\
\text { heart failure score }\end{array}$ & 39.3 & 41.4 & 30.9 & 38.8 & 21.4 & 6.3 & 29.4 \\
\hline \multicolumn{8}{|l|}{ Variables at 18 months } \\
\hline \multicolumn{8}{|c|}{ Left ventricular ejection fraction, \% } \\
\hline Median & 26.4 & 25.9 & 33.7 & 30.1 & 227.7 & 16.2 & 58.6 \\
\hline $\begin{array}{l}25 \text { th and } 75 \text { th } \\
\text { percentiles }\end{array}$ & $22.2 / 32.3$ & $21.6 / 31.0$ & $27.7 / 41.7$ & $25.3 / 35.3$ & & & \\
\hline Pulse pressure & 46.7 & 46.6 & 52.2 & 48.8 & 11.8 & 4.7 & 40.1 \\
\hline $\begin{array}{l}\text { Systolic blood pressure, } \\
\mathrm{mm} \mathrm{Hg}, \text { mean } \pm \mathrm{SD}\end{array}$ & $120.1 \pm 19.4$ & $116.9 \pm 20.0$ & $126.2 \pm 19.7$ & $121.2 \pm 15.4$ & & & \\
\hline $\begin{array}{l}\text { Diastolic blood pressure, } \\
\mathrm{mm} \mathrm{Hg}, \text { mean } \pm \mathrm{SD}\end{array}$ & $73.4 \pm 28.8$ & $70.3 \pm 9.4$ & $74.0 \pm 10.6$ & $72.4 \pm 10.5$ & & & \\
\hline
\end{tabular}

intrinsic conduction and found that in some characteristics, there was no difference and others, there was a trend for the formula to give worse outcomes.

Second, the Rhythm II ICD [47] study used echocardiographic maximization of LVOT VTI to identify a VV delay as optimal. No difference was found between groups, although the study did not report whether the method of optimization had good test-retest reproducibility. Without confirmation that test-retest reproducibility is high, it is very possible, given the known beat-to-beat variability of VTI, that the allocation among VV delay settings in the optimized group largely the play of chance rather than identification of a true optimum setting for that patient (i.e., one that persists over at least a few minutes, or ideally months). The hazards of uncritically hoping that an apparent optimum is a consistent optimum have been quantified recently [48].

Finally, the Insync III [49] study showed that with VV optimization, a population of CRT patients showed a greater increment in exercise capacity than a similar group of historical controls (MIRACLE study), and a modest improvement in stroke volume compared to the nominal VV delay. In other respects including symptom class and QoL score, there were no differences. Interestingly, although the distribution of observed optima between LV-first and RV-first or simultaneous remained unchanged between the start and the end of the study, it is not reported whether individual patients retained the same optima. Without this information on whether patients retested had the same optima as before, or only just drawn from the 
same distribution, it is again unfortunately not possible to tell whether the optimization process was identifying a persistent feature of each individual, or drawing from a random distribution with a mean of approximately 0 .

Overall, the VV optimization trial outcomes seem woefully unsupportive of the belief that VV timing is the critical benefit of CRT. The only way they might be supportive of an important role of $\mathrm{VV}$ timing is if $0 \mathrm{~ms}$ (typically used as a control setting) is in fact a very good value for most patients, and the various apparent optimization methods through being unreliable are selecting suboptimal settings.

But even still, it is difficult to discount the precise measurements of hemodynamic effects that have been made during $\mathrm{AV}$ and $\mathrm{VV}$ optimization conducted in the identical patients, which show that the AV adjustments have many times larger an effect on blood pressure than VV adjustments [24]. With hemodynamic techniques, where high numbers of replicates are easily obtained, the error bars are small. The effect of adjustment of VV delay is therefore easily verified to be much smaller (by several fold) than the effect of adjustment of AV delay. Neither the VV optimization trials nor the high-precision optimization studies, therefore, support an important role for resynchronization of the ventricles as the main benefit of biventricular pacing.

\section{Conclusions}

The direct effects of biventricular pacing are purely electrical; mechanical effects occur only through myocardial responses to activation. Meanwhile, electrical abnormalities such as QRS prolongation are habitually measured with high precision, while mechanical abnormalities are measured with low precision (or, worse, to an unknown precision). These two reasons act to make electrical features of the patient intrinsically better candidates than mechanical features, for predicting benefit of biventricular pacing. It is therefore not surprising that electrical abnormalities such as long PR interval and wide QRS, which are unambiguous to detect and change instantly with pacing, are persistently useful predictors of benefit from CRT.

The relative contribution of AV optimization versus VV synchronization to the overall improvement in hemodynamics and clinical endpoints may vary between individuals and may depend on QRS width and intrinsic AV interval. These variables together with heart rate play an important role in maximizing left ventricular filling time, a consistent predictor of acute and long term response.

However, because of the inextricable linkage between $\mathrm{AV}$ and VV timings, it is very difficult to quantify beyond doubt the relative contribution to improvements of these two electrical abnormalities, using standard clinical data. From the evidence that we have seen so far and discussed in this review, it appears that they may contribute approximately equally. The abbreviation CRT, although, snappy, may be doing us a disservice by focusing the mind on resynchronization (making structures, i.e., the ventricles, beat at the same time) and thereby encouraging neglect of the powerful contribution these devices make to AV delay adjustment.

The time may have come to abandon the above term in favor of a neutral one. For those favoring three-letter acronyms and neologisms to achieve a patina of sophistication, we suggest "Cardiac Euchronization Therapy" (CET), which recognizes that timings are being changed to make them better, rather than necessarily synchronous. Legitimately this can be applied to AV delay improvement as well as ventricular resynchronization.

Alternatively, there is an older term whose meager merits are only that it is well-known, concise and factually correct: atriobiventricular pacing [50].

Acknowledgments Dr. Kyriacou (FS/08/027/24763), Dr. Pabari (PG/08/114) and Dr. Francis (FS/10/038) are supported by fellowships from the British Heart Foundation. The authors are grateful to the UK's NIHR Biomedical Research Centre scheme and the BHF Research Excellence Award scheme.

Open Access This article is distributed under the terms of the Creative Commons Attribution Noncommercial License which permits any noncommercial use, distribution, and reproduction in any medium, provided the original author(s) and source are credited.

\section{References}

1. Cleland JG, Daubert JC, Erdmann E, Freemantle N, Gras D, Kappenberger $L$ et al (2005) The effect of cardiac resynchronization on morbidity and mortality in heart failure. N Engl J Med 352:1539-1549

2. Young JB, Abraham WT, Smith AL et al (2003) Combined cardiac resynchronization and implantable cardioversion defibrillation in advanced chronic heart failure: the MIRACLE ICD trial. JAMA 289:2685-2694

3. Abraham WT, Fisher WG, Smith AL et al (2002) Cardiac resynchronization in chronic heart failure. $\mathrm{N}$ Engl $\mathrm{J}$ Med 346:1845-1853

4. Cazeau S, Leclercq C, Lavergne T et al (2001) Effects of multisite biventricular pacing in patients with heart failure and intraventricular conduction delay. N Engl J Med 344:873-880

5. Bristow MR, Saxon LA, Boehmer J, Krueger S, Kass DA, De Marco T, Carson P, DiCarlo L, DeMets D, White BG, DeVries DW, Feldman AM, Comparison of Medical Therapy, Pacing, and Defibrillation in Heart Failure (COMPANION) Investigators (2004) Cardiac-resynchronization therapy with or without an implantable defibrillator in advanced chronic heart failure. N Engl J Med 350(21):2140-2150

6. Fox M, Mealing S, Anderson R, Dean J, Stein K (2007) A price and RS Taylor. The clinical effectiveness and cost-effectiveness of cardiac esynchronisation (biventricular pacing) for heart 
failure: systematic review and economic model. Health Technol Assess 11(47):256-274

7. Salo RW, Auricchio A (2003) Topic review: mechanisms of benefit in pacing of patients in heart failure. Herzschrittmachertherapie und Elektrophysiologie 10(1):16-22. Doi: $10.1007 / \mathrm{s} 003990050044$

8. Weber KT, Brilla CG (1991) Pathological hypertrophy and cardiac interstitium: fibrosis and renin-angiotensin-aldosterone system. Circulation 83:1849-1865

9. Salo RW, Auricchio A, Salo MD, Sommariva L, Chiariello L (1997) Modification of restrictive mitral filling patterns in congestive heart failure by dual chamber pacing. PACE 18:907 (abstract 447)

10. Rutishauser W, Wirz P, Gander M, Luthy E (1966) Atriogenic diastolic reflux in patients with atrioventricular block. Circulation 34:807-817

11. Rokey R, Murphy DJ, Nielsen AP, Abinader KG, Huhta JC, Quinones MA (1986) Detection of diastolic atrioventricular valvular regurgitation by pulsed Doppler echocardiography and its association with complete heart block. Am J Cardiol 57:692-694

12. Panidis IP, Ross J, Munley B, Nestico P, Mintz GS (1986) Diastolic mitral regurgitation in patients with atriovencular conduction abnormalities: a common finding by Doppler echocardiography. J Am Coll Cardiol 7:768-774

13. Schnittger I, Appleton CP, Hatle LK, Popp RL (1988) Diastolic mitral and tricuspid regurgitation by Doppler echocardiography in patients with atrioventricular block: new insight into the mechanism of atrioventricular valve closure. Am J Coll Cardiol 11:83-88

14. Xiao HB, Lee CH, Gibson DG (1991) Effect of left bundle branch block on diastolic function in dilated cardiomyopathy. Br Heart $\mathrm{J}$ 66:443-447

15. Xiao HB, Brecker SJD, Gibson DG (1992) Effect of abnormal activation on the time course of the left ventricular pressure pulse in dilated cardiomyopathy. Br Heart J 68:403-407

16. Xiao HB, Roy C, Gibson DG (1994) Nature of ventricular activation in patients with dilated cardiomyopathy: evidence for bilateral bundle branch block. Br Heart J 72:167-174

17. Xiao HB, Brecker SJD, Gibson DG (1993) Differing effects of right ventricular pacing and left bundle branch block on left ventricular function. Br Heart J 69:166-173

18. Meisner JS, McQueen DM, Ishida Y, Vetter HO, Bortolotti U, Strom JA, Frater RWM, Peskin CS, Yellin EL (1985) Effects of timing of atrial systole on LV filling and mitral valve closure: computer and dog studies. Am J Physiol 249:H604-H619

19. Mbassouroum M, O‘Sullivan C, Brecker SJ, Xiao HB, Gibson DG (1992) Shortened filling time in dilated cardiomyopathy; additional effects on heart rate variability. $\mathrm{Br}$ Heart $\mathrm{J}$ 36(17):236-241

20. Bogaard MD, Kirkels JH, Hauer RN, Loh P, Doevendans PA, Meine M (2010) Should we optimize cardiac resynchronization therapy during exercise? J Cardiovasc Electrophysiol 21:1307-1316

21. Whinnett ZI, Davies JE, Willson K, Chow AW, Foale RA, Davies DW, Hughes AD, Francis DP, Mayet J (2006) Determination of optimal atrioventricular delay for cardiac resynchronization therapy using acute non-invasive blood pressure. Europace 8(5):358-366

22. Whinnett ZI, Briscoe C, Davies JE, Willson K, Manisty $\mathrm{CH}$, Davies DW, Peters NS, Kanagaratnam P, Hughes AD, Mayet J, Francis DP (2008) The atrioventricular delay of cardiac resynchronization can be optimized hemodynamically during exercise and predicted from resting measurements. Heart Rhythm 5(3):378-386

23. Whinnett ZI, Davies JE, Nott G, Willson K, Manisty CH, Peters NS, Kanagaratnam P, Davies DW, Hughes AD, Mayet J, Francis DP (2008) Efficiency, reproducibility and agreement of five different hemodynamic measures for optimization of cardiac resynchronization therapy. Int J Cardiol 129(2):216-226

24. Whinnett ZI, Davies JE, Willson K, Manisty CH, Chow AW, Foale RA, Davies DW, Hughes AD, Mayet J, Francis DP (2006) Haemodynamic effects of changes in atrioventricular and interventricular delay in cardiac resynchronisation therapy show a consistent pattern: analysis of shape, magnitude and relative importance of atrioventricular and interventricular delay. Heart 92(11): $1628-1634$

25. Hochleitner M, Hortnagl H, Ng CK, Hortnagl H, Gschnitzer F, Zechmann W (1990) Usefulness of physiologic dual-chamber pacing in drug-resistant idiopathic dilated cardiomyopathy. Am J Cardiol 66:198-202

26. Brecker SJ, Xiao HB, Sparrow J, Gibson DG (1992) Effects of dual-chamber pacing with short atrioventricular delay in dilated cardiomyopathy. Lancet 340(8831):1308-1312. Erratum in: Lancet 340(8833): 1482

27. Nishimura RA, Hayes DL, Holmes DR Jr, Tajik AJ (1995) Mechanism of hemodynamic improvement by dual-chamber pacing for severe left ventricular dysfunction: an acute Doppler and catheterization hemodynamic study. J Am Coll Cardiol 25(2):281-288

28. Leclercq C, Cazeau S, Le Breton H et al (1998) Acute hemodynamic effects of biventricular DDD pacing in patients with end-stage heart failure. J Am Coll Cardiol 32:1825-1831

29. Auricchio A, Ding J, Spinelli JC, Kramer AP, Salo RW, Hoersch W, KenKnight BH, Klein HU (2002) Cardiac resynchronization therapy restores optimal atrioventricular mechanical timing in heart failure patients with ventricular conduction delay. J Am Coll Cardiol 39(7):1163-1169

30. Gold MR, Feliciano Z, Gottlieb SS, Fisher ML (1995) Dualchamber pacing with a short atrioventricular delay in congestive heart failure: a randomized study. J Am Coll Cardiol 26(4): 967-973

31. Kass DA, Chen CH, Curry C, Talbot M, Berger R, Fetics B, Nevo E (1999) Improved left ventricular mechanics from acute VDD pacing in patients with dilated cardiomyopathy and ventricular conduction delay. Circulation 99(12):1567-1573

32. Butter C, Auricchio A, Stellbrink C, Fleck E, Ding J, Yu Y, Huvelle E, Spinelli J, Pacing Therapy for Chronic Heart Failure II Study Group (2001) Effect of resynchronization therapy stimulation site on the systolic function of heart failure patients. Circulation 104(25):3026-3029

33. Derval N, Steendijk P, Gula LJ, Deplagne A, Laborderie J, Sacher F, Knecht S, Wright M, Nault I, Ploux S, Ritter P, Bordachar P, Lafitte S, Réant P, Klein GJ, Narayan SM, Garrigue S, Hocini M, Haissaguerre M, Clementy J, Jaïs P (2010) Optimizing hemodynamics in heart failure patients by systematic screening of left ventricular pacing sites: the lateral left ventricular wall and the coronary sinus are rarely the best sites. J Am Coll Cardiol 55(6):576-578

34. van Gelder BM, Bracke FA, Meijer A, Pijls NH (2005) The hemodynamic effect of intrinsic conduction during left ventricular pacing as compared to biventricular pacing. J Am Coll Cardiol 46(12):2305-2310

35. Yu CM, Chan JY, Zhang Q, Omar R, Yip GW, Hussin A, Fang F, Lam KH, Chan HC, Fung JW (2009) Biventricular pacing in patients with bradycardia and normal ejection fraction. $\mathrm{N}$ Engl $\mathrm{J}$ Med 361(22):2123-2134

36. Upadhyay GA, Choudhry NK, Auricchio A, Ruskin J, Singh JP (2008) Cardiac resynchronization in patients with atrial fibrillation: a meta-analysis of prospective cohort studies. J Am Coll Cardiol 52(15):1239-1246

37. Wein S, Voskoboinik A, Wein L, Billah B, Krum H (2010) Extending the boundaries of cardiac resynchronization therapy: efficacy in atrial fibrillation, New York heart association class II, 
and narrow QRS heart failure patients. J Card Fail 16(5):432-438 Epub 2010 Feb 11

38. Hoppe UC, Casares JM, Eiskjaer H, Hagemann A, Cleland JG, Freemantle N, Erdmann E (2006) Effect of cardiac resynchronization on the incidence of atrial fibrillation in patients with severe heart failure. Circulation 114(1):18-25

39. Moss AJ, Hall WJ, Cannom DS, Klein H, Brown MW, Daubert JP, Estes NAM, Foster E, Greenberg H, Higgins SL, Pfeffer MA, Solomon SD, Wilber D, Zareba W, For the MADIT-CRT Trial Investigators (2009) Cardiac-resynchronization therapy for the prevention of heart-failure events. N Engl J Med 361:1329-1338

40. Linde C, Abraham WT, Gold MR, John Sutton M, Ghio S, Daubert C, On behalf of the REVERSE (REsynchronization reVErses Remodeling in Systolic left vEntricular dysfunction) Study Group (2008) Randomized trial of cardiac resynchronization in mildly symptomatic heart failure patients and in asymptomatic patients with left ventricular dysfunction and previous heart failure symptoms. J Am Coll Cardiol 52:1834-1843

41. Chung ES, Leon AR, Tavazzi L, Sun JP, Nihoyannopoulos P, Merlino J, Abraham WT, Ghio S, Leclercq C, Bax JJ, Yu CM, Gorcsan J III, John Sutton M, De Sutter J, Murillo J (2008) Results of the predictors of response to CRT (PROSPECT) trial. Circulation 117(20):2608-2616

42. Van Bommel RJ, Bax JJ, Abraham WT, Chung ES, Pires LA, Tavazzi L, Zimetbaum PJ, Gerritse B, Kristiansen N, Ghio S (2009) Characteristics of heart failure patients associated with good and poor response to cardiac resynchronization therapy: a PROSPECT (Predictors of Response to CRT) sub-analysis. Eur Heart J 30(20):2470-2477

43. Bleeker GB, Mollema SA, Holman ER, Van de Veire N, Ypenburg C, Boersma E, van der Wall EE, Schalij MJ, Bax JJ (2007) Left ventricular resynchronization is mandatory for response to cardiac resynchronization therapy: analysis in patients with echocardiographic evidence of left ventricular dyssynchrony at baseline. Circulation 116(13):1440-1448

44. Beshai JF, Grimm RA, Nagueh SF, Baker JH II, Beau SL, Greenberg SM, Pires LA, Tchou PJ, RethinQ Study Investigators
(2007) Cardiac-resynchronization therapy in heart failure with narrow QRS complexes. N Engl J Med 357(24):2461-2471

45. Gervais R, Leclercq C, Shankar A, Jacobs S, Eiskjaer H, Johannessen A, Freemantle N, Cleland JG, Tavazzi L, Daubert C, CARE-HF Investigators (2009) Surface electrocardiogram to predict outcome in candidates for cardiac resynchronization therapy: a sub-analysis of the CARE-HF trial. Eur J Heart Fail 11(7):699-705

46. Rao RK, Kumar UN, Schafer J, Viloria E, De Lurgio D, Foster E (2007) Reduced ventricular volumes and improved systolic function with cardiac resynchronization therapy: a randomized trial comparing simultaneous biventricular pacing, sequential biventricular pacing, and left ventricular pacing. Circulation $115: 2136-2144$

47. Boriani G, Muller CP, Seidl KH, Grove R, Vogt J, Danschel W, Schuchert A, Djiane P, Biffi M, Becker T, Bailleul C, Trappe HJ, Resynchronization for the HemodYnamic Treatment for Heart Failure Management II Investigators (2006) Randomized comparison of simultaneous biventricular stimulation versus optimized interventricular delay in cardiac resynchronization therapy. The resynchronization for the HemodYnamic treatment for heart failure management II implantable cardioverter defibrillator (RHYTHM II ICD) study. Am Heart J 151:1050-1058

48. Pabari PA, Willson K, Stegemann B, van Geldorp IE, Kyriacou A, Moraldo M, Mayet J, Hughes AD, Francis DP (2010) When is an optimization not an optimization? Evaluation of clinical implications of information content (signal-noise ratio) in optimization of cardiac resynchronization therapy, and how to measure and maximize it. Heart Fail Rev 66(14):1256-1271

49. Leon AR, Abraham WT, Brozena S, Daubert JP, Fisher WG, Gurley JC, Liang CS, Wong G, For the InSync III Clinical Study Investigators (2005) Cardiac resynchronization with sequential biventricular pacing for the treatment of moderate-to-severe heart failure. J Am Coll Cardiol 46:2298-2304

50. Cleland JG, Nasir M, Tageldien A (2007) Cardiac resynchronization therapy or atrio-biventricular pacing-what should it be called? Nat Clin Pract Cardiovasc Med 4(2):90-101, Review 